\title{
Dietary intake and body mass index in HIV-positive and HIV-negative drug abusers of Hispanic ethnicity
}

\author{
Janet E Forrester*, Katherine L Tucker and Sherwood L Gorbach \\ Department of Family Medicine and Community Health, Tufts University School of Medicine, 136 Harrison Avenue, \\ Boston, MA 02111, USA
}

Submitted 13 November 2003: Accepted 2 March 2004

\begin{abstract}
Objective: Malnutrition in drug abusers has been attributed to poor diet. However, previous studies are conflicting. Many studies have not considered possible concurrent HIV disease. The purpose of this study was to determine the relationship between drug abuse and dietary intake in Hispanic Americans with and without HIV infection.

Design: Dietary intake was measured using 3-day food records and 24-hour dietary recalls in three groups: HIV-positive drug abusers, HIV-negative drug abusers and HIV-positive persons who do not use drugs ('non-drug abusers').

Setting: The baseline data from a prospective cohort study of the role of drug abuse in HIV/AIDS weight loss and malnutrition conducted in Boston, Massachusetts, USA. Subjects: The first 284 participants to enrol in the study.

Results: HIV-positive drug abusers had a body mass index (BMI) that was significantly lower than that of HIV-positive non-drug abusers. Reported energy, fat and fibre intakes did not differ between groups. All groups had median reported intakes of vitamin $A$, vitamin $B_{6}$, vitamin $B_{12}$, selenium and zinc that were in excess of the dietary reference values (DRI). Intakes of $\alpha$-tocopherol were below the DRI, but did not differ from intakes of the general US population. However, increasing levels of drug abuse were associated with lower reported intakes of vitamin $\mathrm{B}_{6}$, vitamin $\mathrm{B}_{12}$, selenium and zinc.

Conclusions: Overall, this study does not support the notion that dietary intake can explain the lower BMI of HIV-positive drug abusers. Further studies examining nondietary determinants of nutritional status in drug abusers are warranted.
\end{abstract}

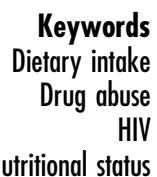

Poor nutritional status is common in drug abusers with and without HIV infection ${ }^{1-11}$ and it has been suggested that nutrition interventions be integrated into drug rehabilitation programmes.

While dietary insufficiency is the most probable cause, some studies suggest that diet alone cannot entirely explain nutritional problems in this population. Smit et al. $^{12}$ found that both HIV-positive and HIV-negative drug abusers in Baltimore, Maryland, USA, reported involuntary weight loss despite ingesting in excess of $1 \mathrm{kcal}$ more than the US National Health and Nutrition Examination Survey (NHANES) estimates of intake for a healthy population of similar racial composition. In a previous study, we found that HIV-positive women who were intravenous drug abusers reported higher energy intakes, but significantly lower body mass index (BMI), than HIV-positive women who did not abuse drugs ${ }^{13}$. In a German homeless population, drug abuse and wasting diseases, such as HIV, cancer or tuberculosis, but not food intake, were associated with poor nutritional status ${ }^{14}$. These studies contradict the findings of other work showing the diet of drug abusers to be poor ${ }^{8,15,16}$. Possible reasons for contradictions among studies may include differences in the types of drug used, differences in the frequency of drug use, and differences in the populations examined. Many studies have looked at the diet of drug abusers enrolled in rehabilitation or detoxification programmes, while others have examined free-living drug-abusing populations. Patients of detoxification programmes may be heavier drug users than the drugabusing population as a whole. In addition, some studies have not tested drug abusers for HIV. Since HIV is an important cause of weight loss and loss of appetite, it is not clear to what extent poor dietary intake and nutritional status can be directly attributed to drug abuse per se.

In this study, we examined the dietary intake and BMI of Hispanic drug abusers with HIV. We compared the diets of HIV-positive drug abusers with those of HIV-negative drug 
abusers and HIV-positive persons who do not use drugs ('non-drug abusers'). We assessed the relationship between diet and the specific type of drugs used, as well as the frequency of drug abuse. We also examined other factors that could impinge on diet in this population, including alcohol use, depression and homelessness. We chose to study Hispanics because of the importance of drug abuse as a risk factor for HIV among Hispanics of the North Eastern USA: about $85 \%$ of Hispanic men and $40 \%$ of Hispanic women with AIDS in this region report drug abuse as their primary risk factor (HIV/AIDS Bureau, Massachusetts Department of Public Health, unpublished data). By studying an ethnically homogeneous group we avoided the possible interfering effects of ethnic influence on diet or patterns of drug abuse.

\section{Methods}

\section{Participants}

All participants were of self-identified Hispanic ethnicity. Study interviews were conducted in Spanish by bilingual Hispanic personnel. Recruitment was done through outreach in streets, homeless shelters, health clinics and physician offices. We were careful to recruit eligible adults only on the basis of their HIV status or their drug abuse habits, and without reference to their nutritional status. Participants learned that the study was about nutrition only after they had been screened for eligibility. Hispanic adults ( $\geq 18$ years) who spoke Spanish fluently were considered eligible. The exclusion criteria were pregnant at recruitment, non-HIV associated malignancies, and refusal to sign a consent form to release medical records. Two individuals who had a history of hormone treatments for a sex change were excluded from the study. Participants were seen at the General Clinical Research Center of the New England Medical Center in Boston. All participants gave informed consent. The study was approved by the Institutional Review Board of the Tufts-New England Medical Center.

\section{Assessments}

The data were collected at two clinic visits about 10 days apart. At the first visit, information on housing, medical insurance, HIV history, HIV medications, smoking, alcohol consumption and drug abuse was collected by standardised interview. Depression was measured using the Burnam depression screen ${ }^{17}$. Homelessness was defined as living in a homeless shelter or on the streets. Persons who reported living with a friend or at someone else's house were not considered to be homeless since access to cooking facilities would not be limited.

At the first visit, a 24-hour dietary recall was performed, and instructions on how to maintain a 3-day food record were given. At the second visit, the 3-day food record was reviewed with the participant for completeness. If the study participant was unable to keep a 3-day food record or the record was of poor quality, a second 24-hour dietary recall was done. Interviewers received extensive training in dietary data collection from the supervisors of the nutrition team and were observed at six-monthly intervals to ensure data quality. The food items documented by $24-$ hour recall or 3-day food record were converted into nutrients using the Nutrition Data System for Research software (The Minnesota Nutrition Data System; Nutrition Coordinating Center, School of Public Health, Minneapolis, MN, USA). The dietary data reported are the average intakes from the first 24-hour recall and the 3-day food record (average of 4 days) for those participants who provided complete data, or the average of the first and second 24-hour dietary recalls (average of 2 days) for those participants who did not provide a 3-day food record. The diet data from 11 participants were missing.

Since we were most interested in the dietary factors that lead to wasting or poor immune status, we focused the analyses on a restricted number of dietary factors including energy intake and the macronutrient composition of the diet. Micronutrients that have been implicated in poor outcomes in HIV include vitamin A (measured as retinol equivalents, thereby including carotenoids), vitamin $\mathrm{E}$, vitamin $\mathrm{B}_{6}$, vitamin $\mathrm{B}_{12}$, selenium and zinc. Fibre was used as a measure of overall dietary quality since fibre is found in beans, whole-grain foods, fruits and vegetables. To better assess the dietary intake of macronutrients from food, the percentage of energy for each macronutrient was calculated excluding the contribution from alcohol. The percentage of the recommended micronutrient intake was calculated using the age- and gender-specific dietary reference intakes (DRIs) published in the US Dietary Reference Intake Reports ${ }^{18-20}$ and included intake from dietary supplements, unless otherwise indicated. Since the values for the micronutrient intakes were skewed, we report the median, 25th and 75th percentiles.

Drug use was determined by standardised interview, using a questionnaire that included items related to the type, mode and frequency of drug use. A participant was considered a drug abuser if he or she reported having used any one of heroin, cocaine, 'speedball' (heroin with cocaine) or methadone (prescription and non-prescription use) by any route at least once in the past six months. Other drugs, such as amphetamines, inhalants or barbiturates, were not considered in this study because the frequency of their use was low in this population. Persons who reported marijuana use only were classified with the non-users because marijuana and its legal derivatives are used as appetite stimulants among persons infected with HIV. The frequency of drug abuse was calculated as the highest frequency use among all the drugs reported by any one participant, and was measured on a seven-point scale ranging from less than once per month to more than once per day. Self-reported HIV status was confirmed by enzyme-linked immunosorbent assay. 


\section{Statistical analyses}

Data were analysed separately for men and women. Micronutrient intake is expressed as the median (25th, 75 th percentile) of the percentage of the DRI. Alcohol is expressed as the median (25th, 75th percentile) of the reported grams of intake. For the continuous variables with a normal distribution, differences among the groups were tested using the least-squares means option in SAS version 9.0 (SAS Institute, Cary, NC, USA), in the generalised linear models procedure. Covariates were added to the analyses where indicated. Continuous data with a non-normal distribution were log-transformed and the analyses conducted on the transformed data. When transformation did not adequately normalise the data, non-parametric tests were used. For categorical variables, chi-square or Fisher exact tests were used, where appropriate.

\section{Results}

There were 284 participants enrolled in the study as of 25 October 2003. Two hundred and five (72\%) were born in Puerto Rico, 46 (16\%) were born in the mainland USA and the remaining 33 were born in other parts of Latin America or the Caribbean. The proportion of participants born in other parts of Latin America or the Caribbean did not differ between the study groups $(P=0.44)$.

Among the men, HIV-positive drug abusers and HIVpositive non-drug abusers were significantly older than HIV-negative drug abusers (Table 1). The HIV-positive drug abusers and non-drug abusers had been infected with HIV for a similar number of years, and had similar levels of CD4 counts. A smaller proportion of HIV-positive drug abusers were taking highly active anti-retroviral therapy (HAART) than were HIV-positive non-drug abusers. HIV-positive drug abusers had a BMI significantly lower than that of HIV-positive non-drug abusers. HIV-negative drug abusers were less likely to have a primary care doctor or medical insurance (private or public) than HIV-positive men. The differences in rates of homelessness were a consequence of our recruitment methods, as we recruited many of the HIV-negative drug abusers from homeless shelters. Among the women, the HIV-negative drug abusers were significantly younger than the HIV-positive non-drug abusers. There were no other significant differences among the groups (Table 2).

The drugs most frequently used were heroin and cocaine. Forty-eight per cent of the drug users reported using a combination of heroin and cocaine alone or mixed together ('speedball'). Amphetamine use was reported by 13 participants, and always in conjunction with either cocaine or heroin use. Seventy-one per cent of the drug abusers reported drug use of at least once per day.

Reported use of marijuana - not considered drug abuse in this study - or its legal derivatives was higher in the drug abusers than in the non-drug abusers (HIV-positive drug abusers 27\%; HIV-positive non-drug abusers 12\%; HIV-negative drug abusers 49\%; $P<0.0001$ ).

Depression was common among the participants: $46 / 72$ women (64\%) and 127/212 men (60\%) were classified as depressed.

\section{Dietary intake in men}

Energy, fat and fibre intakes did not differ among the three groups of men, but HIV-negative drug abusers ate significantly less protein and more carbohydrate (including more simple carbohydrate), as a percentage of energy intake excluding alcohol, than did the HIV-positive nondrug abusers (Table 3). Alcohol consumption was highly skewed: most men reported little to no alcohol intake while a few men reported high levels of alcohol intake. However, there was no significant difference among the groups in the median level of alcohol consumption. A smaller proportion of HIV-negative drug abusers reported taking supplements compared with the HIVpositive men. HIV-negative drug abusers reported intakes of vitamin $\mathrm{A}, \alpha$-tocopherol and vitamin $\mathrm{B}_{12}$ that were significantly lower than those of the HIV-positive

Table 1 Characteristics of the men. Data are expressed as mean (standard error), except where indicated otherwise

\begin{tabular}{lccc}
\hline & $\begin{array}{c}\text { Group 1 } \\
\text { HIV-positive } \\
\text { Characteristic }\end{array}$ & $\begin{array}{c}\text { Group 2 } \\
\text { HIV-positive } \\
\text { drug abusers }\end{array}$ & $\begin{array}{c}\text { Group 3 } \\
\text { HIV-negative } \\
\text { drug abusers }\end{array}$ \\
\hline Number in group & 71 & 60 & 81 \\
Age (years) & $41.0(0.99)^{\mathrm{a}}$ & $40.2(1.1)^{\mathrm{a}}$ & $36.7(0.92)$ \\
Years with HIV* & $9.3(6.1,12.3)$ & $7.8(5.3,11.4)$ & - \\
CD4 counts* & $262(158,452)$ & $367(207,527)$ & $931(692,1140)$ \\
HAART use (\%) & $38(54)^{\mathrm{b}}$ & $49(82)$ & - \\
Body mass index $\left(\mathrm{kg} \mathrm{m}^{-2}\right)$ & $25.2(3.5)^{\mathrm{c}}$ & $27.0(5.2)^{\mathrm{c}}$ & $25.8(4.2)$ \\
Medical insurance $(\%)$ & $66(94)^{\mathrm{d}}$ & $53(87)$ & $59(73)$ \\
Homeless $(\%) \dagger$ & $14(20)$ & $0(0)$ & $47(58)$ \\
\hline
\end{tabular}

HAART - highly active anti-retroviral therapy.

*Values are median (25th, 75th percentile).

†Differences in rates of homelessness were a consequence of recruitment strategies.

${ }^{a}$ Group 1 vs. Group 3, $P=0.002$; Group 2 vs. Group 3, $P=0.02$.

${ }^{\mathrm{b}}$ Group 1 vs. Group 2, $P=0.0007$.

${ }^{c}$ Group 1 vs. Group 2; $P=0.01$; Group 2 vs. Group 3, $P=0.09$.

${ }^{\mathrm{d}}$ Chi-square test of differences, $P=0.0008$. 
Table 2 Characteristics of the women. Data are expressed as mean (standard error), except where indicated otherwise

\begin{tabular}{lccc}
\hline & $\begin{array}{c}\text { Group 1 } \\
\text { HIV-positive } \\
\text { drug abusers }\end{array}$ & $\begin{array}{c}\text { Group 2 } \\
\text { HIV-positive } \\
\text { non-drug abusers }\end{array}$ & $\begin{array}{c}\text { Group 3 } \\
\text { HIV-negative } \\
\text { drug abusers }\end{array}$ \\
\hline Number in group & 14 & 37 & 21 \\
Age (years) & $36.1(2.2)$ & $38.1(1.4)^{\mathrm{a}}$ & $33.0(1.9)$ \\
Years with HIV* & $5.0(1.5,8.9)$ & $6.3(3.9,8.6)$ & - \\
CD4 count* & $431(302,531)$ & $424(218,576)$ & $1075(835,1301)$ \\
HAART use (\%) & $5(36)$ & $22(59)$ & - \\
Body mass index $\left(\mathrm{kg} \mathrm{m}^{-2}\right)$ & $27.1(1.9)$ & $29.7(1.2)$ & $30.8(1.5)$ \\
Medical insurance $(\%)$ & $13(93)$ & $35(95)$ & $18(86)$ \\
Homeless $(\%) \dagger$ & $2(14)$ & $4(11)$ & $5(24)$
\end{tabular}

HAART - highly active anti-retroviral therapy.

*Values are median (25th, 75th percentile).

$\dagger$ Differences in rates of homelessness were a consequence of recruitment strategies.

${ }^{a}$ Group 2 vs. Group 3, $P=0.03$.

non-drug abusers, and intakes of vitamin $\mathrm{B}_{6}$ and vitamin $\mathrm{B}_{12}$ that were significantly lower than those reported by the HIV-positive drug abusers. Despite these differences, the men in all groups, on average, were meeting the DRI for vitamins $\mathrm{A}, \mathrm{B}_{6}, \mathrm{~B}_{12}$, selenium and zinc. There were no differences in reported vitamin intake between the HIVpositive drug abusers and the HIV-positive non-drug abusers. The average intakes of $\alpha$-tocopherol were below the recommended values in all three groups.

\section{Dietary intake in women}

Among the women, HIV-positive non-drug abusers ate proportionally more protein than the women - either HIV-positive or HIV-negative - who used drugs (Table 4).
They also ate more fibre and less simple carbohydrate than the HIV-negative drug abusers. There were no significant differences in energy intake among the three groups of women. HIV-negative drug abusers had lower intakes of vitamin $\mathrm{A}$ and vitamin $\mathrm{B}_{6}$, but there was no difference in vitamin intake between the HIV-positive women who were drug abusers and the HIV-positive women who were not drug abusers.

\section{Influence of drug type and frequency on dietary intake in men and women}

There were no differences in energy intake or energyadjusted fibre intake between drug abusers who used cocaine (alone or in 'speedball') and strictly opiate users.

Table 3 Dietary intake* in relation to HIV status and drug abuse in the men. Data are expressed as mean (standard error), except where indicated otherwise

\begin{tabular}{|c|c|c|c|}
\hline Characteristic & $\begin{array}{l}\text { Group } 1 \\
\text { HIV-positive } \\
\text { drug abusers }\end{array}$ & $\begin{array}{c}\text { Group } 2 \\
\text { HIV-positive } \\
\text { non-drug abusers }\end{array}$ & $\begin{array}{l}\text { Group } 3 \\
\text { HIV-negative } \\
\text { drug abusers }\end{array}$ \\
\hline Number in group & 71 & 60 & 81 \\
\hline Did a 3-day food record (\%) & $40(57)$ & $32(54)$ & $32(40)$ \\
\hline Energy (kcal) & $2671(108)$ & $2536(118)$ & $2734(107)$ \\
\hline Protein (\% energy) & $15.1(0.36)$ & $15.9(0.39)^{a}$ & $14.7(0.35)$ \\
\hline Carbohydrate (\% energy) & $54.2(0.83)$ & $52.2(0.91)^{\mathrm{b}}$ & $54.9(0.82)$ \\
\hline Simple carbohydrate (\% energy) & $24.0(1.0)$ & $23.0(0.96)^{\mathrm{C}}$ & $26.1(0.95)$ \\
\hline Fat (\% energy) & $31.6(0.63)$ & $32.6(0.69)$ & $31.1(0.62)$ \\
\hline Fibre $(g) \dagger$ & $19.6(0.72)$ & $18.9(0.79)$ & $18.3(0.72)$ \\
\hline Alcohol $(\mathrm{g}) \ddagger$ & $0.018(0,0.21)$ & $0.020(0,0.16)$ & $0.073(0,0.33)$ \\
\hline Supplement use (\%) & $24(34)$ & $26(44)$ & $11(15)$ \\
\hline Vitamin A (\% DRI)‡ & $116(66,183)$ & $149(80,212)^{d}$ & $103(64,149)$ \\
\hline$\alpha$-Tocopherol (\% DRI) & $72(47,130)$ & $97(53,177)^{e}$ & $63(45,79)$ \\
\hline Vitamin $\mathrm{B}_{6}(\% \mathrm{DRI}) \ddagger$ & $205(139,265)^{f}$ & $197(143,273)$ & $168(135,219)$ \\
\hline Vitamin $B_{12}(\%$ DRI) $\ddagger$ & $233(150,384)^{g}$ & $247(160,440)^{9}$ & $202(104,310)$ \\
\hline Selenium (\% DRI)‡ & $249(194,351)$ & $256(206,338)$ & $268(219,331)$ \\
\hline Zinc (\% DRI) & $131(88,160)$ & $119(90,171)$ & $111(87,144)$ \\
\hline
\end{tabular}

DRI - Dietary Reference Intake.

${ }^{*}$ Reported without contribution from alcohol.

$\dagger$ Fibre adjusted for energy.

$\ddagger$ Values are median (25th, 75th percentile).

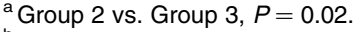

${ }^{b}$ Group 2 vs. Group 3, $P=0.03$

${ }^{c}$ Group 2 vs. Group 3, $P=0.03$.

dGroup 2 vs. Group 3, $P=0.001$

e Group 2 vs. Group 3, $P=0.005$

${ }^{\dagger}$ Group 1 vs. Group 3, $P=0.03$

${ }^{g}$ Group 1 vs. Group 3, $P=0.05$; Group 2 vs. Group 3, $P=0.03$. 
Table 4 Dietary intake* in relation to HIV status and drug abuse in the women. Data are expressed as mean (standard error), except where indicated otherwise

\begin{tabular}{|c|c|c|c|}
\hline Characteristic & $\begin{array}{c}\text { Group } 1 \\
\text { HIV-positive } \\
\text { drug abusers }\end{array}$ & $\begin{array}{c}\text { Group } 2 \\
\text { HIV-positive } \\
\text { non-drug abusers }\end{array}$ & $\begin{array}{c}\text { Group } 3 \\
\text { HIV-negative } \\
\text { drug abusers }\end{array}$ \\
\hline Number in group & 14 & 37 & 21 \\
\hline Did a 3-day food record (\%) & $4(29)$ & $26(70)$ & $5(24)$ \\
\hline Energy (kcal) & $2171(158)$ & $1852(99)$ & $2102(137)$ \\
\hline Protein (\% energy) & $13.2(0.73)^{\mathrm{a}}$ & $15.4(0.46)^{\mathrm{a}}$ & $13.2(0.60)$ \\
\hline Carbohydrate (\% energy) & $56.6(2.0)$ & $54.1(1.3)$ & $54.5(1.7)$ \\
\hline Simple carbohydrate (\% energy) & $26.5(2.4)$ & $23.3(1.5)^{b}$ & $28.1(2.0)$ \\
\hline Fat (\% energy) & $31.4(1.5)$ & $31.6(0.94)$ & $33.4(1.2)$ \\
\hline Fibre $(\mathrm{g}) \dagger$ & $13.9(1.6)$ & $15.9(0.98)^{\mathrm{a}}$ & $11.6(1.3)$ \\
\hline Alcohol $(g) \ddagger$ & $0.008(0,0.38)$ & $0.01(0,0.17)^{d}$ & $0.09(0,0.27)$ \\
\hline Supplement use (\%) & $3(33)$ & $7(34)$ & $3(19)$ \\
\hline Vitamin A (\% DRI)‡ & $110(80,235)$ & $107(51,195)$ & $79(56,119)^{\mathrm{e}}$ \\
\hline$\alpha$-Tocopherol (\% DRI) $\ddagger$ & $49(34,104)$ & $42(32,57)$ & $43(27,72)$ \\
\hline Vitamin $\mathrm{B}_{6}(\% \mathrm{DRI}) \mp$ & $187(120,213)^{f}$ & $140(104,201)^{f}$ & $107(77,136)$ \\
\hline Vitamin $B_{12}(\%$ DRI $) \ddagger$ & $156(93,327)$ & $149(85,219)$ & $124(83,173)$ \\
\hline Selenium (\% DRI) $\ddagger$ & $229(116,281)$ & $183(140,245)$ & $173(123,223)$ \\
\hline Zinc (\% DRI)‡ & $127(80,221)$ & $110(85,166)$ & $88(68,121)$ \\
\hline
\end{tabular}

DRI - Dietary Reference Intake.

${ }^{*}$ Reported without contribution from alcohol.

†Fibre adjusted for energy.

$\ddagger$ Values are median (25th, 75th percentile).

${ }^{a}$ Group 1 vs. Group 2, $P=0.02$; Group 2 vs. Group 3, $P=0.006$.

${ }^{\mathrm{b}}$ Group 2 vs. Group 3, $P=0.06$

${ }^{\mathrm{c}}$ Group 2 vs. Group 3, $P=0.01$.

${ }^{\mathrm{d}}$ Group 2 vs. Group 3, $P=0.03$.

${ }^{\mathrm{e}}$ Group 1 vs. Group 3, $P=0.05$

${ }^{\dagger}$ Group 1 vs. Group 3, $P=0.02$; Group 2 vs. Group 3, $P=0.007$.

Nor did energy or energy-adjusted fibre intake differ according to the frequency of drug use. Increased drug use appeared to be related to increased variability in caloric intake. Men who used drugs at a low frequency (less than once per month to once per week) had energy intakes that varied from 1727 to $4861 \mathrm{kcal} \mathrm{day}^{-1}$, while men who used drugs more frequently (more than once per week to more than once per day) had intakes that varied from 807 to $5883 \mathrm{kcal} \mathrm{day}^{-1}$. However, the difference in variability was not significant at the 0.05 level $(P=0.26)$. In analyses that were adjusted for energy, increased drug frequency was associated with lower reported intakes of vitamin $\mathrm{B}_{6}$ $(P=0.003)$, vitamin $\mathrm{B}_{12}(P=0.05)$, selenium $(P=0.02)$ and zinc $(P<0.007)$. These conclusions were not altered by removing the contribution of dietary supplements from intake values.

\section{Other determinants of dietary intake}

Using multivariate models we examined the role of homelessness and depression on dietary intake. Homeless participants reported an average energy intake 445 (standard error (SE) 129) $\mathrm{kcal} \mathrm{day}^{-1}$ greater than that of participants who were not homeless $(P=0.0006)$. Homelessness was also associated with a 1.3\% (SE 0.43) lower percentage of energy from protein $(P=0.002)$, a $2.6 \%$ (SE 1.0) higher percentage of energy from carbohydrate $(P=0.01)$ and a $3.6 \%$ (SE 1.2) higher percentage of energy from simple carbohydrate in the diet $(P=0.003)$. There was no relationship between energy intake and depression. These conclusions were not altered when we excluded alcohol from energy intake.

Based on the above results, we re-analysed the between-group differences in energy, fibre and macronutrient intakes while adjusting for between-group rates of homelessness. The previously observed differences in percentages of energy from protein, carbohydrate and simple carbohydrate between the male HIV-negative drug abusers and the HIV-positive groups disappeared. Adding homelessness to the models did not alter any of our conclusions regarding the dietary intake of the women, nor our conclusions about the association between the frequency of drug use and reported micronutrient intakes. Accounting for differences among the groups in the type of diet record collected (24-hour dietary recall plus 3-day food record vs. two 24-hour dietary recalls) also did not alter our conclusions.

\section{Discussion}

In this study of Hispanic drug abusers with and without HIV, drug abuse did not appear to influence the dietary intake of energy, fat or the quality of the diet as measured by fibre. The HIV-negative men who abused drugs reported proportionally less protein and more carbohydrate in their diets (excluding alcohol), but this was attributable to homelessness and not drug abuse per se. It is possible that homeless shelters and soup kitchens provide meals that are relatively high in carbohydrate 
compared with the typical diet consumed by these Hispanic adults. Alternatively, homeless men may buy food in convenience stores more often than do men who are not homeless. The foods found in convenience stores tend to be high in carbohydrates.

Increasing frequency of drug abuse was associated, independently of homelessness, with lower reported intakes of vitamin $\mathrm{B}_{6}$, vitamin $\mathrm{B}_{12}$, selenium and zinc. This suggests that heavy drug abusers ingest fewer foods from animal sources. Beans are an important form of protein in the Hispanic diet, which could explain why we did not see an influence of high-frequency drug use on protein intake overall. On average, all the men had adequate intakes of micronutrients with the exception of $\alpha$-tocopherol. Intakes of $\alpha$-tocopherol were below the recommended intake in the general US population, and in healthy Hispanics, so that the observed low intake of $\alpha$-tocopherol is not unique to drug abusers ${ }^{18,21,22}$.

As expected, the use of marijuana was higher in drug abusers than in non-drug abusers, even when we counted as marijuana the use of legal medically prescribed derivatives of marijuana. Since marijuana and its derivatives stimulate appetite, we would have expected to find that drug abusers have significantly higher intakes than non-drug abusers. Instead we found no significant differences in intakes, and poorer intakes of some nutrients at higher levels of drug abuse. Thus, differences in rates of marijuana use cannot explain our study findings.

The pattern of dietary intake in Hispanic women would be expected to differ from that of men since women, if they have stable housing, may have more control over the quality of their diet. Notably, HIV-positive non drugabusing women reported better-quality diets than women who were abusing drugs, with proportionally more protein and fibre. However, energy and micronutrient intakes did not differ significantly, with the exception of lower vitamin $\mathrm{B}_{6}$ in the diet of HIV-negative drug-abusing women. This may reflect the higher intake of simple carbohydrates. Himmelgreen et al. found that Hispanic women who used drugs and were living in Hartford, Connecticut (and therefore likely of the same ethnicity as the women in our study), ate vegetables less frequently and sweets or desserts more frequently than Hispanic women who did not use drugs, but were of similar socioeconomic group ${ }^{23}$

Drug abuse involving cocaine (cocaine alone or 'speedball') did not differ in its influence on dietary intake compared with opiates alone. Cocaine has been associated in previous studies with disruptions in eating patterns and eating disorders ${ }^{24,25}$. Heroin abuse has been associated with a substitution of protein and fat for carbohydrates $3,23,25$. Although the HIV-negative drugabusing women ate more carbohydrate, independent of their housing circumstances, we did not observe a similar effect in the men, in whom higher carbohydrate was a reflection of homelessness.
The combination of HIV and drug abuse seemed negatively to influence BMI since BMI was lowest in the HIV-positive drug-abusing men and women, although all groups on average were of normal BMI or obese. Overall, our data suggest that this difference in BMI cannot be attributed to energy intake. Since there were lower rates of HAART use among the HIV-positive drug abusers, they may have suffered from more infections than the non-drug abusers. The CD 4 counts of the HIV-positive drug abusers, a measure of immune status, appeared to be slightly lower than for the HIV-positive non-drug abusers, but this difference was not statistically significant. Differences in immunity would not seem to account for the differences in BMI between the HIV-positive drug-abusing women and the HIV-positive non drug-abusing women, though this possibility cannot be entirely discarded.

The relatively high BMI of the study participants may reflect the level of health care available in the Boston region, including the availability of HAART and prophylactic treatment for diseases prevalent in this population, such as tuberculosis. The availability of HIV medications through the MEDICAID system (state health care for lowincome persons) varies from state to state in the USA. In Massachusetts, HAART is readily available to MEDICAID recipients. Thus, the rates of HIV medication use and general health status of the HIV-positive participants in our study may not be generalisable to countries where HAART is not available or even to other states within the USA. However, the diet and health status of the HIV-negative drug abusers should be generalisable to other populations, both nationally and internationally.

Poor serum micronutrient status is commonly found among both HIV-positive and HIV-negative drug abusers $2,6,9,26-29$. However, previous studies have failed to find strong evidence that diet can entirely explain the poor nutritional status of drug abusers. Other possible explanations include malabsorption, metabolic abnormalities, or increased requirements. The micronutrients vitamin A, vitamin E, the carotenoids, selenium and zinc are of particular interest because of their established role in immunity, and their association with survival in observational studies of $\mathrm{HIV}^{30-34}$. The association of lower selenium intake with increased drug frequency seen in this study is especially worrisome. A low level of serum selenium was independently associated with an almost 20fold increased risk of mortality from HIV in a study of drug abusers in Miami ${ }^{34}$.

We did not compare the results of our study with published data from NHANES because the last published data on Puerto Ricans living in the mainland USA are from 1982-84, now over 20 years old. Since that survey was published, many foods in the USA have been fortified. Although BMI was published in those reports, the rates of obesity in the USA have been climbing steadily, and therefore the published data from 1982-84 likely do not reflect average values today. 
We expected to find that drug abusers consume significantly more alcohol than non-drug abusers. The rate of excessive alcohol use appeared to be about the same regardless of HIV status or drug-abusing habits. Thus, our data do not support the notion that abuse of cocaine or heroin is strongly associated with alcohol abuse in this population.

This study has strengths over previous studies of the dietary intake of drug abusers. The study was specifically designed to examine the dietary intake of this population. By using an exclusively Hispanic population, we eliminated variability in intake due to differences in ethnic group. Our detailed data on drug abuse allowed us to examine the effects of cocaine and heroin abuse, independently, on diet. The dietary intake data were based on 4 days of intake in the majority of participants, and a minimum of 2 days of intake for the others. However, the data should be considered in the light of several study weaknesses. First, we had limited numbers of women in some groups, which made our estimates less reliable and reduced our power to examine differences. Second, 3-day food records and 24-hour dietary recalls may not be good instruments to record intakes of micronutrients that have a highly variable content in foods, such as vitamin A. Therefore, estimated intakes in individuals may be over- or underestimated. The comparison of group means may mitigate this limitation.

In conclusion, our data suggest that while there are some differences in dietary intake that can be attributed to drug abuse, especially among heavy drug abusers, overall, diet cannot seem to explain the high prevalence of lower BMI seen in this study. Therefore, further studies pursuing other explanations of lower BMI in HIV-positive and HIVnegative drug abusers are warranted. These studies should include the examination of non-dietary factors such as malabsorption, metabolic dysfunction and increased requirements, and should account for co-morbidities, such as HIV, as well as the social determinants of poor health associated with drug abuse.

\section{Acknowledgements}

We thank the study team for their hard work and the participants for their trust. This study was supported by the National Institute on Drug Abuse (grant nos. DA 11598 and DA14501), the National Institute of Diabetes \& Digestive \& Kidney Diseases (grant no. DK4 5734-07), the Center for AIDS Research (grant no. 1-P308142853) and the Center for Drug Abuse and AIDS Research (grant no. P30 DA13868-01A1). The General Research Center of the New England Medical Center, Boston, is supported by the Division of Research Resources of the National Institutes of Health (grant no. M01-RR00054).

J.E.F. contributed to the study design, analyses and interpretation of the data. K.L.T. contributed to the study design and interpretation of the data. S.L.G. contributed to the study design and oversight of the project.

\section{References}

1 Aylett P. Some aspects of the nutritional state in 'hard' drug addicts. British Journal of Addiction 1978; 73: 77-81.

2 Nakah A, Frank O, Louria DB, Quinones MA, Baker H. A vitamin profile of heroin addiction. American Journal of Public Health 1979; 69: 1058-60.

3 Morabia A, Fabre J, Chee E, Zeger S, Orsat A, Robert A. Diet and opiate addiction: a quantitative assessment of the diets of non-institutionalized opiate addicts. British Journal of Addiction 1989; 84: 173-80.

4 Varela P, Marcos A, Santacruz I, Ripoll S, Requejo AM. Human immunodeficiency virus infection and nutritional status in female drug addicts undergoing detoxification: anthropometric and immunologic assessment. American Journal of Clinical Nutrition 1997; 66: 504S-8S.

5 Varela P, Marcos A, Ripoll S, Requejo AM, Herrara P, Casas A. Nutritional status assessment of HIV-positive drug addicts. European Journal of Clinical Nutrition 1990; 44: 415-8.

6 Huggins ND, Khaled MA, Cornwell PE, Alvarez JO. Nutritional-status and immune function in cocaine and heroin abusers and in methadone treated subjects. Research Communications in Substances of Abuse 1991; 12: 209-15.

7 McCombie L, Elliott L, Farrow K, Gruer L, Morrison A, Cameron J. Injecting drug use and body mass index [letter]. Addiction 1995; 90: 1117-21.

8 Santolaria-Fernandez FJ, Gomez-Sirvent JL, Gonzalez-Reimers CE, Batista-Lopez JN, Jorge-Hernandez JA, RodriguezMoreno F, et al. Nutritional assessment of drug addicts. Drug and Alcohol Dependence 1995; 38: 11-8.

9 Shor-Posner G, Baum MK. Nutritional alterations in HIV-1 seropositive and seronegative drug users. Nutrition Reviews 1996; 12: 555-6.

10 Baum MK, Shor-Posner G, Zhang G, Lai H, Quesada JA, Campa A, et al. HIV-1 infection in women is associated with severe nutrition deficiencies. Journal of Acquired Immune Deficiency Syndromes and Human Retrovirology 1997; 16: $272-8$.

11 Nazrul Islam SK, Jahangir Hossain K, Ahmed A, Ahsan M. Nutritional status of drug addicts undergoing detoxification: prevalence of malnutrition and influence of illicit drugs and lifestyle. British Journal of Nutrition 2002; 88: 507-13.

12 Smit E, Graham NM, Tang A, Flynn C, Solomon L, Vlahov D. Dietary intake of community-based HIV-1 seropositive and seronegative injecting drug users. Nutrition 1996; 12: 496-501.

13 Forrester JE, Woods MN, Knox TA, Spiegelman D, Skinner SC, Gorbach SL. Body composition and dietary intake in relation to drug abuse in a cohort of HIV-positive persons. Journal of Acquired Immune Deficiency Syndromes and Human Retrovirology 2000; 25: S43-8.

14 Langnäse K, Müller MJ. Nutrition and health in an urban homeless population in Germany. Public Health Nutrition 2001; 4: 805-11.

15 Kraak VI, Sticker JD. Determining the nutritional needs of ethnically diverse urban population with HIV/AIDS. Journal of the American Dietetic Association 1994; (Suppl.) abstract A-60.

16 Gambera SE, Krohn Clarke J. Comments on the dietary intake of drug-dependent persons. Journal of the American Dietetic Association 1976; 68: 155-7.

17 Burnam MA, Wells KB, Leake B, Landsverk J. Development of a brief screening instrument for detecting depressive disorders. Medical Care 1988; 26: 775-89.

18 Food and Nutrition Board, Institute of Medicine. Dietary Reference Intakes for Vitamin C, Vitamin E, Selenium, and 
Carotenoids. Washington, DC: National Academy Press, 2000

19 Food and Nutrition Board, Institute of Medicine. Dietary Reference Intakes for Thiamin, Riboflavin, Niacin, Vitamin $B_{6}$, Folate, Vitamin $B_{12}$, Pantothenic Acid, Biotin and Choline. Washington, DC: National Academy Press, 1998.

20 Food and Nutrition Board, Institute of Medicine. Dietary Reference Intakes for Vitamin A, Vitamin K, Arsenic, Boron, Chromium, Copper, Iodine, Iron, Manganese, Molybdenum, Nickel, Silicon, Vanadium and Zinc. Washington, DC National Academy Press, 2001.

21 Federation of American Societies for Experimental Biology, Life Sciences Research Office. Prepared for the Interagency Board for Nutrition Monitoring and Related Research. Third Report on Nutrition Monitoring in the United States Volume 2. Washington, DC: US Government Printing Office, 1995, $354 \mathrm{pp}$.

22 Mara JE, Bermudez OI, Bacun PJ, Qiao N, Boody-Alter E, Tucker KL. Intake and sources of alpha-tocopherol among US adults. Journal of the American Dietetic Association 2004 104: $567-75$.

23 Himmelgreen DA, Perez-Escamilla R, Segura-Millan S, Romero-Daza N, Tanasescu M, Singer M. A comparison of the nutritional status and food security of drug-using and non-drug using Hispanic women in Hartford, Connecticut. American Journal of Physical Anthropology 1998; 107: 351-61.

24 Jonas JM, Gold MS. Cocaine abuse and eating disorders Lancet 1986; 1(8477): 390-1

25 Mohs ME. Nutritional effects of marijuana, heroin, cocaine, and nicotine. Journal of the American Dietetic Association 1990; 90: 1261-7.
26 Baum MK. The role of micronutrients in HIV-infected intravenous drug abusers. Journal of Acquired Immune Deficiency Syndromes 2000; 25: S49-52.

27 Tang AM, Smit E, Semba RD, Shah N, Lyles CM, Li D, et al. Improved antioxidant status among HIV-infected injecting drug users on potent antiretroviral therapy. Journal of Acquired Immune Deficiency Syndromes 2000; 23: 321-6.

28 Beach RS, Mantero-Atienza E, Shor-Posner G, Javier JJ, Szapocznik J, Morgan R, et al. Specific nutrient abnormalities in asymptomatic HIV infection. AIDS 1992; 6: 701-8.

29 Coodley GO, Coodley MK, Nelson HD, Loveless MO. Micronutrient concentrations in the HIV wasting syndrome. AIDS 1993; 7: 1595-600.

30 Semba RD, Graham NM, Caiaffa WT, Margolick JB, Clement L, Vlahov D. Increased mortality associated with vitamin A deficiency during human immunodeficiency virus type 1 infection. Archives of Internal Medicine 1993; 153: 2149-54.

31 Baum MK, Shor-Posner G, Lu Y, Rosner B, Sauberlich HE, Fletcher MA, et al. Micronutrients and HIV-1 disease progression. AIDS 1995; 9: 1051-6.

32 Tang AM, Graham NM, Saah AJ. Effects of micronutrient intake on survival in human immunodeficiency virus type 1 infection. American Journal of Epidemiology 1996; 143 $1244-56$.

33 Tang AM, Graham NM, Semba RD, Saah AJ. Association between serum vitamin A and E levels and HIV-1 disease progression. AIDS 1997; 11: 613-20.

34 Baum MK, Shor-Posner G, Lai S, Zhang G, Lai H, Fletcher MA, et al. High risk of HIV-related mortality is associated with selenium deficiency. Journal of Acquired Immune Deficiency Syndromes and Human Retrovirology 1997; 15 370-4. 